\title{
ОСОБЛИВОСТІ ЗАСТОСУВАННЯ ТЕХНІЧНИХ ЗАСОБІВ У НАВЧАЛЬНОМУ ПРОЦЕСІ СТУДЕНТІВ 3 ДИСЦИПЛІН «ОСНОВИ ПРАКТИЧНОЇ ДІЯЛЬНОСТІ У ФІЗИЧНІЙ РЕАБІЛІТАЦІЇ (ВСТУП ДО СПЕЦІАЛЬНОСТІ)», «ТЕРАПЕВТИЧНІ ВПРАВИ» І «БІОМЕХАНІКА ТА КЛІНІЧНА КІНЕЗІОЛОГІЯ»
}

\author{
V. I. Bondarchuk, A. V. Bai, K. V. Myndziv, O. V. Vayda \\ I. Horbachevsky Ternopil State Medical University \\ FEATURES OF APPLICATION OF TECHNICAL MEANS IN THE \\ EDUCATIONAL PROCESS OF STUDENTS ON DISCIPLINES: “BASES \\ OF PRACTICAL ACTIVITY IN PHYSICAL REHABILITATION \\ (INTRODUCTION TO THE SPECIALTY)”, “THERAPEUTIC EXERCISES” \\ AND “BIOMECHANICS AND CLINICAL KINESIOLOGY”
}

\begin{abstract}
Анотація. У статті представлено технічні засоби, які використовуються у навчальному процесі на практичних заняттях з дисциплін «Основи практичної діяльності у фізичній реабілітації (Вступ до спеціальності)», «Терапевтичні вправи» і «Біомеханіка та клінічна кінезіологія».

На кафедрі фізичної терапії, ерготерапії та фізичного виховання студенти 1 курсу навчання в Тернопільському державному медичному університеті імені І. Я. Горбачевського МОЗ України вивчають дисципліну «Основи практичної діяльності у фізичній реабілітації (Вступ до спеціальності)». На практичних заняттях під час вивчення тем, які передбачені робочою програмою, студенти вивчають і використовують різноманітні технічні засоби. Для прикладу представлено одну тему, а саме: «Фізична працездатність, визначення поняття. Методи визначення фізичної працездатності», де студенти вивчають: визначення, застосування, обладнання та вимоги до проведення тестів; кількісну оцінку фізичної працездатності; пристрої для тестування; вимоги до проведення навантажувальних тестів для визначення фізичної працездатності; субмаксимальний тест PWC 170 гарвардський степ-тест; тест Наваккі; тест Купера. Для тестування фізичної працездатності на практичному занятті студенти використовують велоергометр вертикальний Circle B6 , тренажер «міні-степпер» та степпер.

Студенти, навчаючись на 2 курсі, вивчають дисципліну «Терапевтичні вправи». На практичних заняттях із вказаної дисципліни студенти вивчають комплекси вправ, які можна застосовувати при різних нозологіях. Адже фізична реабілітація - це застосування фізичних вправ і природних чинників з профілактичною і лікувальною метою у комплексному процесі відновлення здоров’я, фізичного стану та працездатності хворих та інвалідів. На сьогодні існує безліч спеціальних тренажерів для тренування будь-яких м'язів, але, звичайно, неможливо придбати їх усіх, тому студенти для вивчення поданих тем практичних занять використовують спортивний тренажер «Фітнес-центр Максіма», а також велоергометр вертикальний Circle B6; тренажер «міні-степпер» та степпер; пристрій для витягування хребта «NEXUS» та велотренажер магнітний «Кристал BC7200DKG-HB».

Студенти, які навчаються на 3 курсі, вивчають дисципліну «Біомеханіка та клінічна кінезіологія». Мета навчальної дисципліни - сформувати у студентів систему знань про застосування біомеханіки та клінічної кінезіології у професійній діяльності і професії фахівців галузі фізичної терапії, ерготерапії та використання принципів біомеханіки (поведінку і механічні рухи в них на всіх рівнях організації та в різних станах) і клінічної кінезіології (метод діагностики й терапії, який декларує
\end{abstract}

(c) В. І. Бондарчук, А. В. Бай, К. В. Миндзів, О. В. Вайда 
зв’язки м’язового напруження (тонусу) зі станом внутрішніх органів та систем організму). За час вивчення навчальної дисципліни студенти мають можливість відпрацьовувати свої навички на масажних кушетках, приладах, на спортивному тренажері «Фітнес-центр Максіма», на пристрої для витягування хребта «NEXUS» та велотренажері магнітному «Кристал BC7200DKG-HB».

Усі перелічені технічні засоби знаходяться у взаємодії з різними системами організму людини: із системою керування рухами, із системою виконання рухів, із системами обслуговування рухів. Вивчення особливостей застосування технічних засобів у фізичній терапії, ерготерапії на практичних заняттях з дисциплін «Основи практичної діяльності у фізичній реабілітації (Вступ до спеціальності)» (1 курс), «Терапевтичні вправи» (2 курс) та «Біомеханіка та клінічна кінезіологія» (3 курс) є необхідним як інструмент аналізу функціонального стану організму людини.

Ключові слова: фізична терапія; фізична активність; фізичні вправи; прилади; пристосування; тренажери.

Abstract. The study presents the technical means that are used in the educational process in the practical classes of the disciplines: "Fundamentals of Practical Activity in Physical Rehabilitation (Introduction to the specialty)", "Therapeutic Exercises” and "Biomechanics and Clinical Kinesiology".

At the Department of Physical Therapy, Ergotherapy and Physical Education, students of the 1st year of study at I. Horbachevsky Ternopil State Medical University study the discipline "Fundamentals of practical activity in physical rehabilitation (Introduction to the specialty)". In practical classes, students learn how to use a variety of technical tools when studying topics of the work program. For example, the theme "Physical performance, definition of concept. Methods for determining physical performance" is presented where students study: definition, application, equipment and requirements for tests; quantitative assessment of physical performance; devices for testing; requirements for carrying out load tests to determine physical performance; sub-maximal test PWC170; Harvard steppe test; the Navakki test; Cooper test. Students use a Circle B6 vertical ergometer, a mini-stepper trainer and a stepper to test their physical performance on a practical lesson.

Students of the 2nd year learn the discipline "Therapeutic Exercises”. During practical lessons of this discipline students learn complexes of exercises that can be applied to different nosologies. After all, physical rehabilitation is the use of physical exercises and natural factors for preventive and curative purposes in the complex process of restoration of health, physical condition and working capacity of patients and disabled people. Today, there are many special trainers for training any muscles, but of course, it is impossible to buy them all, so students use the Maxima Fitness Center and the Circle B6 vertical ergometer; mini-stepper trainer and stepper; the NEXUS spine stretcher and the BC7200DKG-HB magnetic exercise bike in their studying process.

Students of the 3rd year learn the discipline "Biomechanics and Clinical Kinesiology". The purpose of the course is to create a system of knowledge for students on application of biomechanics and clinical kinesiology in the professional activity and profession of specialists in the field of physical therapy, ergotherapy and the principles of biomechanics (behavior and mechanical movements in them at all levels of organization and in different states) and clinical kinesiology diagnosis and therapy that declares the connection of muscle tension (tone) with the condition of the internal organs and systems of the body. During studying the discipline students have the opportunity to work out their skills using massage couches, devices, the Maxim Fitness Center sports simulator, the NEXUS spine stretcher and the BC7200DKG-HB Magnetic Exercise Bike.

All of the facilities above are in contact with various systems of the human body: with the motion control system, the movement execution system, the movement maintenance systems. Studying and mastering the peculiarities of the use of technical means in physical therapy, erotherapy in practical classes: "Fundamentals of Practical Activity in Physical Rehabilitation (Introduction to the specialty)" (1st year), “Therapeutic Exercises” (2nd year) and “Biomechanics and Clinical Kinesiology” (3rd year), is necessary as a tool for analyzing the functional state of the human body. As there is a need for the application of technical means in the educational process students use: Cycle ergometer vertical Circle B6; Mini-stepper trainer and stepper; Maxim Fitness Center Sports Training Facility; NEXUS Spinner and Magnetic Exercise Bike Magnetic Crystal BC7200DKG-HB in the above mentioned disciplines.

Key words: physical therapy; physical activity; physical exercises; devices; adaptations; simulators.

Вступ. Використання технічних засобів для навчання студентів є одним із найважливіших факторів у фізичній терапії, ерготерапії. Під технічними засобами у навчальному процесі навчання розуміють такі прилади, пристосування, тренажери, тренувальні пристрої, які спрямовані на відновлення функціонального стану людини після оперативних втручань, порушень сенсорних функцій, інсультів, аварій, черепно-мозкових травм, психологічних розладів, перенесених спортивних травм, міозитів, при хворобі Паркінсона i, нарешті, для людей похилого віку. Усі технічні засоби знаходяться у взаємодії з різними системами організму людини: із системою керування рухами (нервовою системою), із системою виконання рухів (опорно-руховим апаратом), із системами обслуговування рухів (серцево-судинною, дихальною, травною, видільною, ендокринною та іншими) [6, 7, 9, 14].

У статті ми представили технічні засоби, які використовуються у навчальному процесі на практичних заняттях з дисциплін «Основи практичної діяльності у фізичній реабілітації (Вступ до спеціальності)», «Терапевтичні вправи» і «Біомеханіка та клінічна кінезіологія». Дисципліни були обрані з робочого навчального плану, який розміщений на сайті Тернопільського державного медичного університету імені І. Я. Горбачевського МОЗ України (далі - Університет) [11]. На практичних заняттях 3 «Основи практичної діяльності у фізичній реабілітації (Вступ до спеціальності)», 1 курс навчання в Університеті, «Терапевтичні вправи», 2 курс навчання в Університеті, і «Біомеханіка та клінічна 
кінезіологія», 3 курс навчання в Університеті, вітчизняні студенти мають можливість використовувати прилади, пристосування, тренажери, тренувальні пристрої, які спрямовані на відновлення функціонального стану людини.

Мета дослідження - представити технічні засоби, які використовуються у навчальному процесі на практичних заняттях $з$ дисциплін «Основи практичної діяльності у фізичній реабілітації (Вступ до спеціальності)», «Терапевтичні вправи» і «Біомеханіка та клінічна кінезіологія», й обгрунтувати доцільність застосування технічних засобів на практичних заняттях.

Методи дослідження. У дослідженні представлені технічні засоби, які використовуються у навчальному процесі на практичних заняттях з дисциплін «Основи практичної діяльності у фізичній реабілітації (Вступ до спеціальності)», «Терапевтичні вправи» і «Біомеханіка та клінічна кінезіологія». Застосовано бібліосистематичний та аналітичний методи в електронних базах даних Science Direct, PubMed, Scopus i Google Scholar. Під час пошуку статті проаналізовано анотації. Критеріями включення були такі: (1) фізична реабілітація i/або фізична терапія, (2) технічні засоби, які використовуються у реабілітації, і (3) документи, написані англійською мовою. Якщо очікуваний критерій був знайдений, повний текст переглядався.

Результати дослідження. На кафедрі фізичної терапії, ерготерапії та фізичного виховання студенти 1 курсу навчання в Університеті вивчають дисципліну «Основи практичної діяльності у фізичній реабілітації (Вступ до спеціальності)» [11]. На практичних заняттях під час вивчення тем, які передбачені робочою програмою, студенти вивчають і використовують різноманітні технічні засоби. Для прикладу представлено одну тему, а саме: «Фізична працездатність, визначення поняття. Методи визначення фізичної працездатності», де студенти вивчають: визначення, застосування, обладнання та вимоги до проведення тестів; кількісну оцінку фізичної працездатності; пристрої для тестування; вимоги до проведення навантажувальних тестів для визначення фізичної працездатності; субмаксимальний тест $\mathrm{PWC}_{170}$; гарвардський степ-тест; тест Наваккі; тест Купера. Для тестування фізичної працездатності на практичному занятті студенти використовують велоергометр вертикальний Circle B6 (рік введення в експлуатацію - 23.12.2016 р., інвентарний номер 10422773), тренажер «міні-степпер» (рік введення в експлуатацію - 30.04.2016 р., інвен- тарний номер 11335439) та степпер (рік введення в експлуатацію - 30.12.2014 р., інвентарний номер 11307791). На кожному з них можна моделювати навантаження різного характеру та потужності.

Розглянемо для прикладу субмаксимальний тест $\mathrm{PWC}_{170}$, який використовується з метою визначення ступеня працездатності організму при пульсі 170 ударів за хвилину. Тест PWC $_{170}$ - абревіатура, складена з перших букв виразу Physical Working Capacity (фізична працездатність). Як вище було вказано, даний тест використовується з метою визначення ступеня працездатності організму при пульсі 170 ударів за хвилину, а вибір саме цієї частоти зумовлений наступним: зона оптимального функціонування серцево-судинної системи в процесі виконання м'язового навантаження знаходиться в межах 170-190 уд./хв; взаємозв’язок між ЧСС і потужністю виконаного фізичного навантаження зберігає лінійний характер до 170 уд./хв; при більш високій ЧСС лінійний характер залежності порушується внаслідок активації анаеробних (гліколітичних) механізмів м'язової діяльності. Тест має назву субмаксимального, бо під час проби не дається навантаження до 170 уд./хв (оскільки занадто високе, тому небезпечне), а два менших навантаження. Потім графічним чи математичним методами визначають величину фізичної працездатності, яка б була в умовах, якби ЧСС досягла рівня 170 скорочень за 1 хв, тобто $\mathrm{PWC}_{170}$ $[3,12]$. На практичному занятті під час вивчення теми студенти для проведення субмаксимального тесту PWC ${ }_{170}$ використовують велоергометр вертикальний Circle B6 (рік введення в експлуатацію 23.12.2016 р., інвентарний номер 10422773), який представлений на рис. 1.

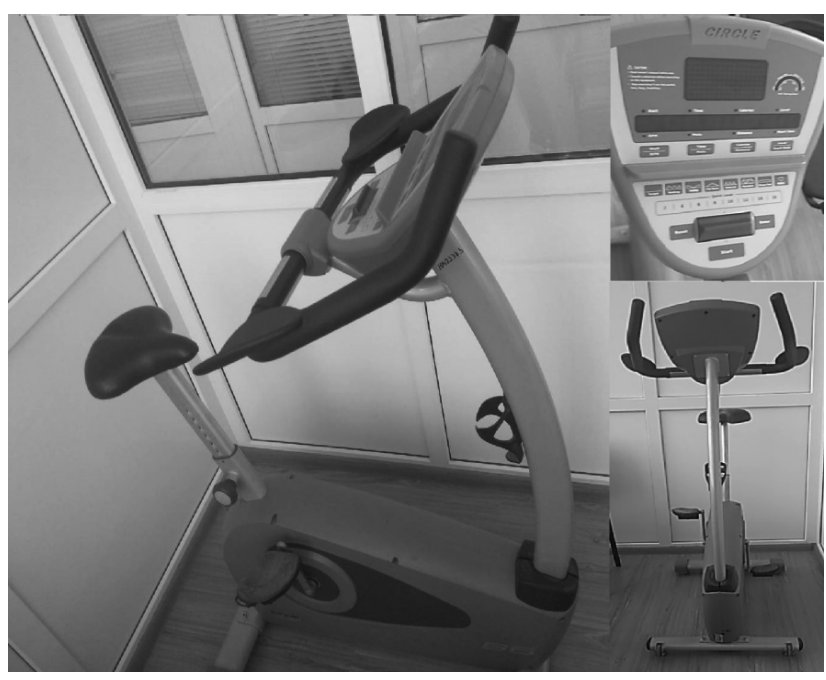

Рис. 1. Велоергометр вертикальний Circle B6. 
Студенти, навчаючись на 2 курсі в Університеті, продовжують активно вивчати нові дисципліни. Згідно з навчальним планом, кількість дисциплін, які студентам викладають на кафедрі фізичної терапії, ерготерапії та фізичного виховання, -5 , у статті ми представили одну дисципліну - «Терапевтичні вправи». На практичних заняттях із вказаної дисципліни студенти вивчають комплекси вправ, які можна застосовувати при різних нозологіях. Адже фізична реабілітація - це застосування фізичних вправ і природних чинників з профілактичною і лікувальною метою у комплексному процесі відновлення здоров'я, фізичного стану та працездатності хворих та інвалідів.

Вивчаючи дисципліну «Терапевтичні вправи», студенти 2 курсу навчання в Університеті повинні знати класифікації вправ, які поділяють: за анатомічною ознакою (для м'язів голови, шиї, рук, ніг, тулуба); за активністю виконання (активні, активні з допомогою і з зусиллям, пасивні, активно-пасивні); за характером вправ (дихальні, коригуючі, на координацію рухів, підготовчі та ін.); за використанням предметів і приладів (без них, з ними, на них). Знаючи класифікації вправ за анатомічною ознакою, за активністю виконання, за характером вправ та за використанням предметів і приладів, студенти застосовують їх на практиці, адже лікувальна дія фізичних вправ багатогранна $[5,10,13]$.

Під час виконання фізичних вправ в організмі відбуваються складні фізіологічні, біомеханічні, психологічні процеси. Будь-яке скорочення м'язів подразнює закладені в них численні нервові закінчення (пропріорецептори). Потік імпульсів з них, а також з рецепторів інших утворень опорно-рухового апарату, спрямовується в центральну нервову систему, змінює її функціональний стан і через вегетативні центри забезпечує регуляцію і перебудову діяльності внутрішніх органів. Одночасно у цьому процесі бере участь і гуморальна система. Продукти обміну речовин, що утворюються у м'язах, потрапляють у кров і діють на нервову систему і залози внутрішньої секреції, викликаючи виділення гормонів. Фізичні вправи мають: тонізуючий (стимулювальний), трофічний, компенсаторний, нормалізуючий вплив на організм хворого $[5,10]$. На сьогодні існує безліч спеціальних тренажерів для тренування будь-яких м'язів, але, звичайно, неможливо придбати їх усіх, тому студенти для вивчення поданих тем практичних занять використовують спортивний тренажер «Фітнес-центр Максіма» (рік введення в експлуатацію - 29.02.2012 р., інвентарний номер 10400790, 10400791), який представлений на рис. 2, а також велоергометр вертикальний Circle B6 - рис. 1; тренажер «міні-степпер» та степпер; велотренажер магнітний «Кристал BC7200DKG-HB» - рис. 3, та пристрій для витягування хребта «NEXUS» - рис. 4.

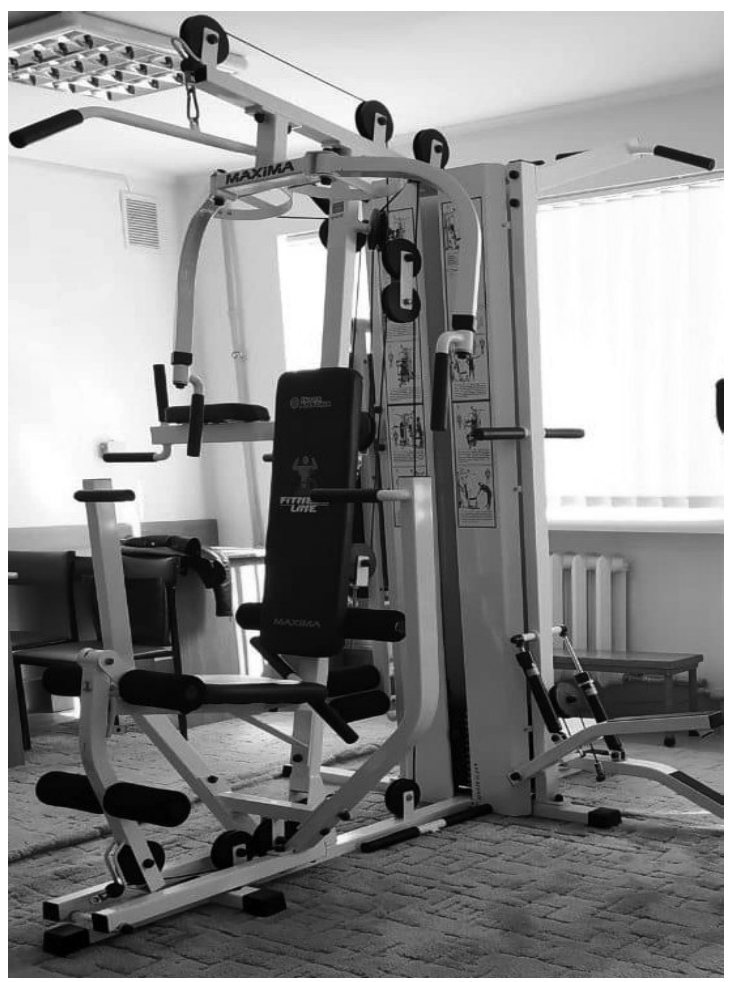

Рис. 2. Тренажер «Фітнес-центр Максіма».

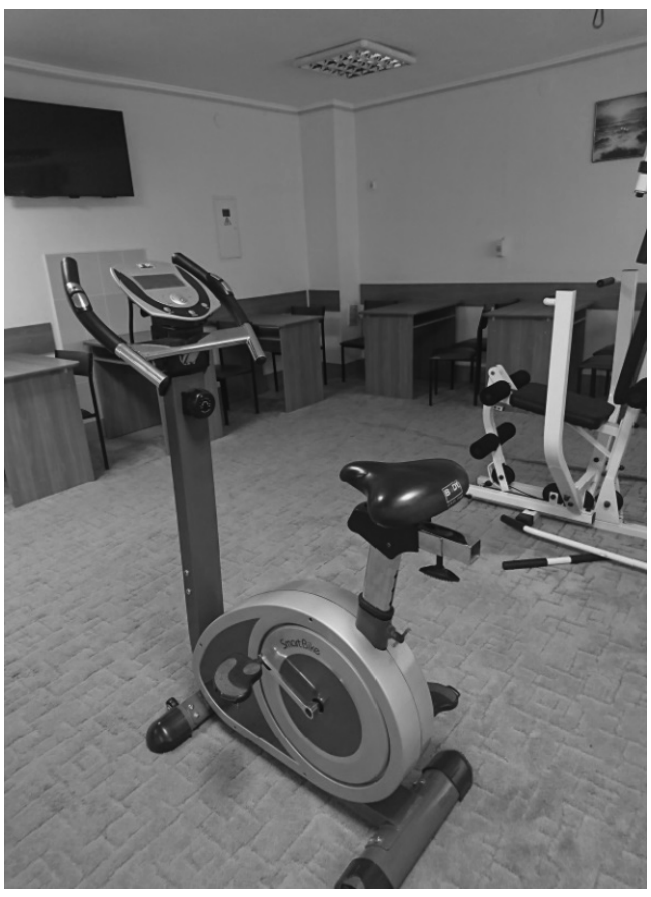

Рис. 3. Велотренажер магнітний «Кристал BC7200DKG-HB». 

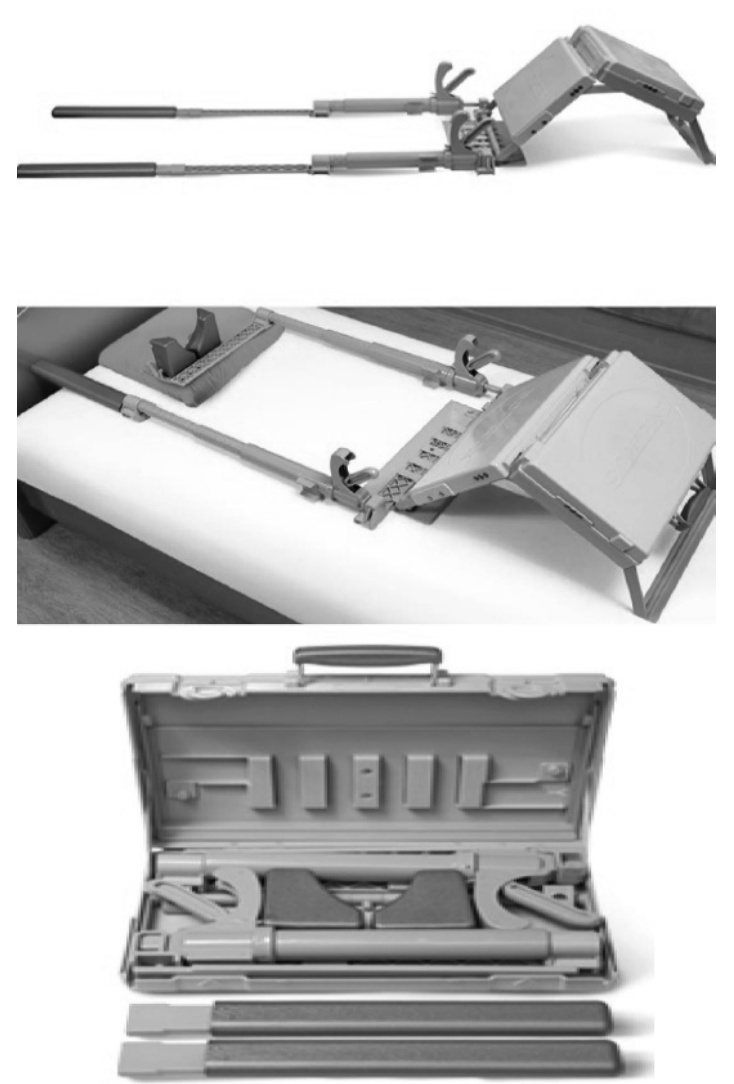

Рис. 4. Пристрій для витягування хребта «NEXUS».

World Confederation for Physical Therapy (WCPT) [15], рис. 5, рекомендує включення широкого спектра дисциплін в освітній стандарт підготовки фізичних терапевтів, у тому числі науки про рух і фізичну активність.

Під керівництвом програмного комітету Конгресу міжнародні високопрофесійні доповідачі залучалися до активного обговорення з широкого кола тем у галузі фізичної терапії. На конгресі WCPT [15] Дж. Льюїс, К. Джинн, А. Кулс, Б. Вічензіно, Дж. Рой у доповіді «MSK: Shoulder and elbow (FS-02)» узагальнили кращі наукові дані про: 1) біль у плечі, який пов' язаний із манжетою ротатора (субакроміальне защемлення та тендинопатія ротаторної манжети) та замороженим плечем; 2) болі в ліктьових суглобах (тенісний лікоть); 3) взаємозв'язок між місцевими структурами та центральною нервовою системою. O’Салливан, Клиона, Шакья, Нищал Ратна у тематиці «Rehabilitation in low-resource countries (DS-04)» вказали, що 80 \% населення світу з інвалідністю проживає у країнах з низьким рівнем доходу. Часто реабілітаційні послуги є рідкісними і не $є$ частиною основної медичної служби. Ключовим фактором посилення глобальних реабілітаційних послуг є забезпечення якісних можливостей для навчання та навчання для працівників реабілітації. Інноваційні підходи до освіти та навчання необхідні для того, щоб якісні послуги з реабілітації були доступні для тих, хто їх потребує. У вказаних темах обговорювалася необхідність мультидисциплінарного підходу із залученням фахівців 3 немедичною освітою, зокрема фахівців фізичної реабілітації (фізичних терапевтів). Адже зміст фізичної терапії передбачає забезпечення послугами приватних осіб та населення загалом, метою якої $\epsilon$ максимально можливий розвиток, підтримання та відновлення рухових функцій або якості функцій організму впродовж усього життя.

Студенти, які навчаються на 3 курсі Університету за спеціальністю 227 «Фізична терапія, ерготерапія», протягом року (I-II семестр) вивчають дисципліну «Біомеханіка та клінічна кінезіологія». Мета навчальної дисципліни - сформувати у студентів систему знань про застосування біомеханіки і клінічної кінезіології у професійній діяльності та професії фахівців галузі фізичної терапії, ерготерапії і використання принципів біомеханіки (поведінку та механічні рухи в них на всіх рівнях організації й у різних станах) і клінічної кінезіології (метод діагностики й терапії, який декларує зв'язки м'язового напруження (тонусу) зі станом внутрішніх органів та систем організму).

Ми запропонували для огляду одну з тем практичного заняття «Біомеханіка травм і захворювань опорно-рухового апарату», яка включає обов'язкове залучення в навчальний процес технічних засобів. Щоб застосувати технічні засоби на практичному занятті, студентам необхідно скласти програму «Система інтегративної кінезіотерапії» відповідно до періоду реабілітації: при вивихах плеча; внутрішньосуглобових переломах ліктьового суглоба; ліктьового суглоба у другому періоді, ушкодженнях колінного, гомілковостопного суглоба, ушкодженнях ахіллового сухожилка, при діафізарних переломах плеча, переломі діафіза кісток передпліччя, переломах променевої кістки в типовому місці, при переломах ключиці, лопатки, кісток кисті. За час вивчення теми навчальної дисципліни студенти мають можливість відпрацьовувати свої навички на масажних кушетках, приладах, на спортивному тренажері «Фітнес-центр Максіма» (рік введення в експлуатацію - 29.02.2012 р., інвентарний номер 10400790, 10400791), який представлений на рис. 2 , а також на пристрої для витягування хребта «NEXUS» (рік введення в експлуатацію - 31.08.2015 р., ін- 
вентарний номер 10420177), рис. 4, велотренажері магнітному «Кристал BC7200DKG-HB» (рік введення в експлуатацію - 29.02.2012 р., інвентарний номер 10400757), рис. 3.

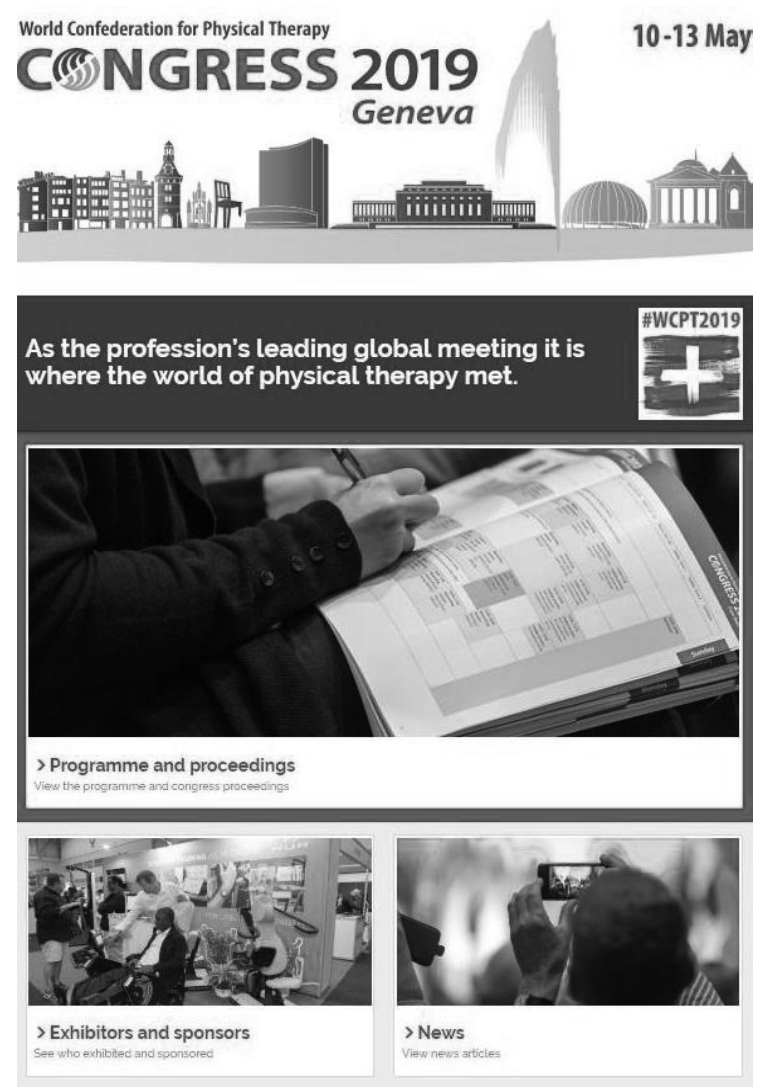

Рис. 5. World Confederation for Physical Therapy, Congress 2019, Geneva.

Під терміном «кінезіотерапевтична програма» розуміють комплекс індивідуально підібраних фізичних вправ, виконання яких забезпечує стійкий відновно-реабілітаційний ефект за рахунок відновлення функціональності пошкоджених м’язів і функцій опорно-рухового апарату. Основу такої програми становлять фізичні вправи з обтяженнями, що виконуються на спеціальних тренажерах, які мають декомпресійний компонент [4, 5, 13].

Для складання оптимальної програми кінезіотерапії насамперед враховують результати кінезіологічної діагностики, окрім цього, беруть до уваги фізичний стан пацієнта, тяжкість захворювання, наявність супутніх патологій, а також структурні та функціональні основи взаємодії м'язів при різних положеннях і рухах тіла, відображені у динамічній анатомії та біомеханіці. За результатами мануального м'язового тестування й корекції розробляється кінезіотерапевтична програма, яка забезпечує активізацію внутрішніх регенераційних і відновних процесів в організмі людини шляхом виконання фізичних вправ. Адже кінезіологія - це один із напрямків у реабілітації, що оптимізує організм людини до тренувальної діяльності за рахунок адаптації організму до зовнішніх подразників і дозволяє максимально використовувати резервні можливості організму за рахунок формування постійного зворотного біологічного зв'язку з організмом. Новизна методу полягає в тому, що запропонована оцінка рефлекторної активності нервової системи в процесі навантаження (мануальне м'язове тестування). Дана методика оцінки активності рефлексу руху, як метод біологічного зворотного зв'язку 3 організмом, була покладена в основу кінезіологічної діагностики [1, 2, 4, 8].

Висновки та перспективи подалыших досліджень. Усі перелічені технічні засоби знаходяться у взаємодії з різними системами організму людини: із системою керування рухами, із системою виконання рухів, із системами обслуговування рухів. Вивчення особливостей застосування технічних засобів у фізичній терапії, ерготерапії на практичних заняттях з дисциплін «Основи практичної діяльності у фізичній реабілітації (Вступ до спеціальності)» (1 курс), «Терапевтичні вправи» (2 курс) та «Біомеханіка та клінічна кінезіологія» (3 курс) є необхідним як інструмент аналізу функціонального стану організму людини. Оскільки є необхідність у застосуванні технічних засобів у навчальному процесі, студенти використовують: велоергометр вертикальний Circle B6; тренажер «міні-степпер» та степпер; спортивний тренажер «Фітнес-центр Максіма»; пристрій для витягування хребта «NEXUS» та велотренажер магнітний «Кристал BC7200DKG-HB» у вивченні вищевказаних дисциплін.

Перспективи подальших досліджень у даному напрямку пов’язані з розширенням світогляду у професії фахівців галузі фізичної терапії, ерготерапії. Також перспективними є подальші дослідження, пов’язані з виявленням прихованих рухових резервів організму, і розроблення ефективних механізмів перенавчання з метою оптимізації виконуваних професійних рухів.

мышечно-скелетной системы / Л. Ф. Васильева. - М. : Роликс, 2012. - 108 с. 
2. Кобелєв С. Ю. Мануальний м’язовий тест - ефективний спосіб визначення сили м'язів для осіб з пошкодженням спинного мозку / С. Ю. Кобелєв // Молода спортивна наука України: зб. наук. праць з галузі фізичної культури та спорту. Вип. 8 : у 4-х т. - Львів : НФВ «Українські технології», 2004. - Т. 2. - С. 455-459.

3. Комісова Т. Є. Вплив різних рухових режимів на фізичну працездатність студентів впродовж навчального року / Т. Є. Комісова, Л. П. Коваленко, А. В. Мамотенко // Біологія та валеологія. - 2017. - Вип. 19. C. 131-140. - URL : http://nbuv.gov.ua/UJRN/znpkhnpu_ bio_2017_19_17.

4. Кравчанко Б. М. Система інтегративної кінезітерапії як сучасний метод фізичної реабілітації при захворюваннях опорно-рухової системи / Б. М. Кравчанко // Спортивна медицина і фізична реабілітація. - 2016. № 2. - С. 66-75.

5. Міхеєнко О. І. Застосування фізичних вправ як засобу оздоровлення / О. І. Міхеєнко, І. В. Козел // Здоров’я людини в сучасному культурно-освітньому просторі : матеріали II Всеукр. дистанційної наук.-практ. інтернетконф. - 2019. - С. 51-55.

6. Моніторинг стану здоров’я за функціональними показниками за допомогою сенсорів у реабілітаційній медицині: систематичний огляд / В. П. Марценюк, I. В. Качур, А. С. Сверстюк [та ін.] // Вісник наукових досліджень. - 2019. - № 2. - С. 5-12.

7. Попадюха Ю. А. Особливості реабілітаційної системи для верхніх кінцівок Bimeо PRO / Ю. А. Попадюха // Науковий часопис Національного педагогічного університету імені М. П. Драгоманова. Серія 15 «Науковопедагогічні проблеми фізичної культури (фізична культура і спорт)» : зб. наук. праць. - 2018. - Вип. ЗК (97). C. 437-442.

\section{References}

1. Vasylyeva, L.F. (2012). Vizualnaya i kineziologicheskaya diagnostika patobiomekhanicheskikh izmeneniy myshechnoskeletnoy sistemy [Visual and kinesiological diagnosis of pathobiomechanical changes in the musculoskeletal system]. Moscow: Roliks [in Russian].

2. Kobeliev, S.Yu. (2004). Manualnyi miazovyi test efektyvnyi sposib vyznachennia syly miaziv dlia osib z poshkodzhenniam spynnoho mozku [Manual muscle test - an effective way to determine muscle strength for people with spinal cord injury]. Moloda sportyvna nauka Ukrainy: Zb. nauk. prats z haluzi fizychnoi kultury ta sportu - Young Sport Science of Ukraine: Coll. of Scien. Works in the Field of Physical Culture and Sports, 8 (2), 455-459 [in Ukrainian].

3. Komisova, T.Ye., Kovalenko, L.P., \& Mamotenko, A. V. (2017). Vplyv riznykh rukhovykh rezhymiv na fizychnu pratsezdatnist studentiv vprodovzh navchalnoho roku [The influence of different movement regimes on the physical
8. Посипкіна А. Ю. Кінезіотерапія після розриву меніску колінного суглобу на післялікарняному періоді: робота на здобуття кваліфікаційного ступеня бакалавра: [спец.] 6.010203 - здоров’я людини / А. Ю. Посипкіна. Суми : СумДУ, 2019. - 31 с.

9. Сущенко О. Теоретичні основи формування професійної компетентності майбутніх фахівців із фізичної реабілітації / О. Сущенко // Педагогічні науки: теорія, історія, інноваційні технології : наук. журн. - 2018. № 4 (78). - С. 226-237.

10. Терещенко О. В. Вплив фізичних вправ на організм студента / О. В. Терещенко // Науковий часопис Національного педагогічного університету імені М. П. Драгоманова. Серія 15 «Науково-педагогічні проблеми фізичної культури (фізична культура і спорт)». - 2016. Вип. 7 (77). - С. 48-50.

11. Тернопільський державний медичний університет імені I. Я. Горбачевського. Навчальний відділ. - URL : https://education.tdmu.edu.ua/about/roboci-navcalni-plani.

12. Хорошуха М. Визначення PWC170 у спортсменів та осіб, які не займаються спортом, за допомогою специфічних навантажень (метод роwег-ергометрії) / М. Хорошуха // Педагогічні науки: теорія, історія, інноваційні технології : наук. журн. - 2018. - № 3 (77). - С. 153-167.

13. Шиян Б. М. Теорія і методика фізичного виховання школярів : підручник / Б. М. Шиян. - Т. : Навчальна книга Богдан, 2008. - Ч. 1. - 272 с.

14. Trunk muscle strength in relation to balance and functional disability in unihemispheric stroke patients / M. Karatas, N. Cetin, M. Bayramoglu, A. Dilek // American Journal of Physical Medicine and Rehabilitation. - 2004. Vol. 83, Issue 2. - P. 81-87.

15. WCPT - Published on World Confederation for Physical Therapy, Congress 2019, Geneva. - URL : https:// www.wcpt.org/wcpt2019.

performance of students during the school year]. Biolohiia ta valeolohiia - Biology and Valeology, 19, 131-140. Retrieved from: http://nbuv.gov.ua/UJRN/znpkhnpu_bio_2017_19_17 [in Ukrainian].

4. Kravchanko, B.M. (2016). Systema intehratyvnoi kineziterapii yak suchasnyi metod fizychnoi reabilitatsii pry zakhvoriuvanniakh oporno-rukhovoi systemy [The system of integrative kinesitherapy as a modern method of physical rehabilitation in diseases of the musculoskeletal system.]. Sports Medicine and Physical Rehabilitation Sports Medicine and Physical Rehabilitation, 2, 66-75 [in Ukrainian].

5. Mikheienko, O.I., \& Kozel, I.V. (2019). Zastosuvannia fizychnykh vprav yak zasobu ozdorovlennia [The use of exercise as a means of healing]. Zdorovia liudyny $v$ suchasnomu kulturno-osvitnomu prostori: materialy II Vseukrainskoi dystantsiinoi naukovo-praktychnoi internet-konferentsii - Human Health in the Modern 
Cultural and Educational Space: Proceedings of the Second All-Ukrainian Remote Scientific and Practical Internet Conference, 51-55 [in Ukrainian].

6. Martseniuk, V.P., Kachur, I.V., Sverstiuk, A.S., Bondarchuk, V.I., Zavidniuk, Yu.V., Koval, V.B., \& Mochulska, O.M. (2019). Monitorynh stanu zdorovia za funktsionalnymy pokaznykamy za dopomohoiu sensoriv u reabilitatsiinii medytsyni: systematychnyi ohliad visnyk naukovykh doslidzhen [Functional health monitoring using sensors in rehabilitation medicine: A systematic review of research bulletin]. Visnyk naukovykh doslidzhen - Bulletin of Scientific Research, 2, 5-12 [in Ukrainian].

7. Popadiukha, Yu.A. (2018). Osoblyvosti reabilitatsiinoi systemy dlia verkhnikh kintsivok Bimeo PRO [Features of the rehabilitation system for the upper extremities Bimeo PRO]. Naukovyi chasopys Natsionalnoho pedahohichnoho universytetu imeni M.P. Drahomanova. Seriia 15: Naukovopedahohichni problemy fizychnoi kultury (fizychna kultura i sport) - Scientific Journal of M.P. Drahomanov National Pedagogical University. Series 15: Scientific and Pedagogical Problems of Physical Culture (Physical Culture and Sport), 3K (97), 437-442 [in Ukrainian].

8. Posypkina, A.Yu. (2019). Kinezioterapiia pislia rozryvu menisku kolinnoho suhlobu na pislialikarnianomu periodi [Kinesiotherapy after fracture of the knee joint meniscus in the post-hospital period]. Work for Bachelor's Degree. Sumy [in Ukrainian].

9. Sushchenko, O. (2018). Teoretychni osnovy formuvannia profesiinoi kompetentnosti maibutnikh fakhivtsiv iz fizychnoi reabilitatsii [Theoretical bases of formation of professional competence of future specialists in physical rehabilitation]. Pedahohichni nauky: teoriia, istoriia, innovatsiini tekhnolohii: naukovyi zhurnal - Pedagogical Sciences: Theory, History, Innovative Technologies: Scientific Journal, 4 (78), 226-237 [in Ukrainian].
10. Tereshchenko, O.V. (2016). Vplyv fizychnykh vprav na orhanizm studenta [The influence of exercise on the student body]. Naukovyi chasopys Natsionalnoho pedahohichnoho universytetu imeni M. P. Drahomanova. Seriia 15: Naukovo-pedahohichni problemy fizychnoi kultury (fizychna kultura i sport) - Scientific Journal of M.P. Dragomanov National Pedagogical University. Series 15: Scientific and Pedagogical Problems of Physical Culture (Physical Culture and Sport), 7 (77) 16, 48-50 [in Ukrainian].

11. I. Horbachevsky Ternopil State Medical University. Navchalnyi viddil - Training Department. Retrieved from: https://education.tdmu.edu.ua/about/roboci-navcalni-plani [in Ukrainian].

12. Khoroshukha, M. (2017). Vyznachennia PWC170 u sportsmeniv ta osib, yaki ne zaimaiutsia sportom, za dopomohoiu spetsyfichnykh navantazhen (metod powererhometrii) [Determination of PWC170 in athletes and non-athletes using specific loads (power-ergometry method)]. Pedahohichni nauky: teoriia, istoriia, innovatsiini tekhnolohii: naukovyi zhurnal - Pedagogical Sciences: Theory, History, Innovative Technologies: Scientific Journal, 3 (77), 153-167 [in Ukrainian].

13. Shyian, B.M. (2008). Teoriia i metodyka fizychnoho vykhovannia shkoliariv [Theory and methodology of physical education of students]. Ternopil: Navchalna knyha "Bohdan” [in Ukrainian].

14. Karatas, M., Cetin, N., Bayramoglu, M., \& Dilek, A. (2004). Trunk muscle strength in relation to balance and functional disability in unihemispheric stroke patients. American Journal of Physical Medicine and Rehabilitation, 83 (2), 81-87.

15. Published on World Confederation for Physical Therapy, Congress 2019. Geneva. Retrieved from: https:// www.wcpt.org/wcpt2019. 